\title{
Norteamericanización de Brasil
}

\author{
North Americanization of Brazil
}

\author{
Marcos Cueto \\ Instituto de Estudios Peruanos \\ Roca Bologna 633 \\ Lima 18, Peru
}

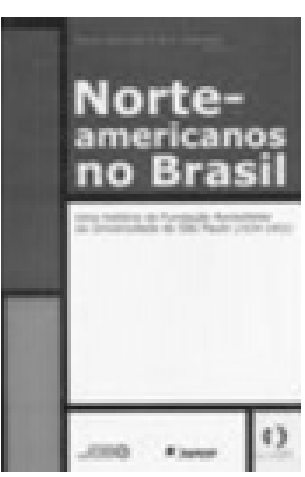

María Gabriela S. M. C. Marinho

Norte-americanos no Brasil: uma bistória da Fundação Rockefeller na Universidade de São Paulo (1934-1952),

São Paulo, Editora Autores Associados 2001, 196p.
$\mathrm{E}$ n los últimos años han parecido varios y valiosos estudios sobre el papel de la Fundación Rockefeller, una institución creada en 1913, en la organización del conocimiento científico, la reforma de la enseñanza médica y la ejecución de campañas de salud internacionales. Originalmente, las primeros investigaciones se concentraban en el lado emisor, o norteamericano, y enfatizaban las motivaciones del mismo. Las motivaciones mas tradicionales eran las humanitarias y filantrópicas y las explicaciones mas críticas presentaban el programa de la Rockefeller como un medio más sofisticado para proteger e incrementar la productividad de las economías ligadas al capitalismo norteamericano y controlar a las élites locales a través de los sutiles mecanismos de la hegemonía cultural. Sin embargo, desde hace algunos pocos años los estudios sobre la relación entre la fundación y la ciencia se extendieron a varios países del mundo donde nuevos estudios empezaron a enfatizar el papel de la Rockefeller en los procesos locales de recepción, negociación y diferenciación entre grupos profesionales competitivos. Este importante libro de Marinho es ciertamente una contribución notable a esta renovada perspectiva de estudiar el impacto de la Rockefeller desde lo local.

El tema del libro es también de suma importancia para la historia de la educación superior, la ciencia y la medicina en el Brasil y la región latinoamericana: el desarrollo de una de las primeras universidades que adopto la organización, los objetivos y el estilo norteamericanos. Este fue parte de un proceso de 'americanización' más amplio que marcó la ciencia médica latinoamericana del siglo XX. Un proceso en gran parte inspirado en un modelo conocido como "flexneriano" que data de 1910. Este modelo de enseñanza médica enfatizaba la limitación del número de estudiantes de medicina, la creación de puestos de tiempo completo para que los profesores puedan dedicarse exclusivamente a la enseñanza y la investigación, la promoción de la investigación en el laboratorio y en las ciencias básicas, la estrecha asociación entre el hospital utilizado para las practicas clínicas y la enseñanza, entre otras características. La decisión de los brasileros de seguir este modelo fue ciertamente tempranamente inusual en un medio donde las elites profesionales estaban acostumbradas a educarse tratando imitando a los franceses, o europeos, que ponían más énfasis en la práctica y el prestigio profesional. Sin embargo hacia mediados del siglo XX, la gran mayoría de las universidades médicas de la región estaban encaminadas tras los mismos objetivos de origen norteamericano.

La autora se concentra en el período de 1934 a 1952 y en el análisis de las relaciones entre la Universidad de São Paulo y la Fundación 
Rockefeller, aunque ofrece un panorama general de que ocurría antes, al mismo tiempo en otras instituciones, y después del periodo de la investigación. Es importante resaltar que la Fundación Rockefeller tuvo una temprana relación con Sao Paulo. Poco después de su creación, la fundación alentó a comienzos de 1918 la creación de un moderno instituto de higiene en São Paulo, que atrajo a profesores norteamericanos e impulso investigaciones en un área que competía por autonomía y prestigio con la medicina. Eventualmente, esta fue la base institucional sobre la que se creo en 1946 la actual Facultad de Salud Pública de la universidad.

Uno de los aspectos más interesantes de este magnifico libro es la cuidadosa atención a los médicos e intelectuales paulistas que actúan como bisagras o como los llama la autora "articuladores y parceiros" de la filantropía científica. Los dos más destacados son Ernesto de Souza Campos y Zeferino Vaz. De Souza Campos, ex-becario de la Rockefeller en la Universidad de Johns Hopkins, fue un ideólogo que preconizo las bondades del sistema americano y su superioridad sobre el modelo educativo francés. Vaz cumplió un papel destacado en la creación y dirección de la Facultad de Medicina de Ribeirão Preto, adonde fueron a enseñar connotados investigadores de toda la región.

Otro de las virtudes de este libro es la cuidadosa investigación en fuentes locales. Esto incluye cuantiosa y extraordinaria documentación inédita de archivos de la Unicamp, de la Universidad de São Paulo, y CPDOC. Sólo en la reitoria de la Facultad de Medicina de São Paulo se recogieron más de 1,500 páginas durante la investigación. El sólo hecho de basarse fundamentalmente en esta documentación brasilera marca a este libro con una aproximación diferente a la de los primeros estudios de la Rockefeller que sólo se basaban en fuentes metropolitanas.

Sin embargo, tengo una crítica metodológica a este trabajo que no puedo dejar de mencionar. Al parecer el autor no ha utilizado los extraordinarios archivos de la fundación que se encuentran en el Rockefeller Archive Center en Nueva York. Quizás no hubo medios ni oportunidades para hacerlo y esto es comprensible. Pero hubiera sido mejor si el autor explicase en la introducción que hay un repositorio importante más ligado al tema, que no pudo ser consultado, y que eventualmente su exploración puede enriquecer los asuntos tratados en el libro. En todo caso lo bueno de la investigación histórica es que siempre quedan temas pendientes, como la posibilidad de integrar fuentes y perspectivas metropolitanas y locales. Debemos agradecer a la autora por enseñarnos y por sugerirnos mas preguntas en este excelente libro. 